\title{
VILÉM FLUSSER: ENTRE A TRADUÇÃO COMO CRIAÇÃO DE SI E A PÓS-TRADUÇÃO
}

\author{
Márcio Seligmann-Silva* \\ Universidade Estadual de Campinas
}

\begin{abstract}
Resumo: Os textos de Vilém Flusser aqui referidos perpassam seus conceitos de tradução, elucidando seu olhar através do panorama contemplado por um construtor de pontes, aquele que possibilita a troca, ou seja, o ir e vir. Alguns desses conceitos, presentes também na obra benjaminiana, encontram em Flusser o fomento necessário, incorporam-se, entrelaçam-se, completam-se e evoluem, muitas vezes ressignificando-se. Flusser assinala que estamos em uma era pós-reprodução e, sendo assim, na cultura da pós-tradução, elevando, assim, o indivíduo pós-histórico, moldado além da tradição benjaminiana e romântica, antes por ele mesmo absorvida. Segundo ele, a era das imagens eletrônicas agregou mutações e novos problemas ao tradutor, porém o próprio Flusser percebeu e absorveu essas oscilações.
\end{abstract}

Palavras-chave: Vilém Flusser. Tradução. Benjaminiana.

\section{VILÉM FLUSSER: BETWEEN TRANSLATION AS CREATION OF ITSELF AND POST-TRANSLATION}

Abstract: The texts by Vilém Flusser treated in this paper run through his concept of translation, enlightening his view through the panorama envi-

\footnotetext{
* Formação em História, Pontifícia Universidade Católica de São Paulo. Mestrado em Letras (Língua e Literatura Alemã), Universidade de São Paulo. Doutorado em Teoria Literária e Literatura Comparada, Freie Universität Berlin. Pós-Doutorado em Teoria Literária, Zentrum Für Literaturforschung Berlim. Pós-Doutorado em Teoria Literária, Yale. Professor livre-docente do Instituto de Estudos da Linguagem, Universidade Estadual de Campinas. Campinas, São Paulo, Brasil. E-mail: m.seligmann@uol.com.br
} 
saged by a builder of bridges, the one who enables the exchange, i.e., the comings and goings. Some of these concepts, also present in Benjamin's work, find the necessary fomentation in Flusser, incorporating, intertwining, completing and evolving themselves, very often re-signifying themselves. Flusser points out that we are in a post-reproduction era and, as such, in the culture of post-translation, thus elevating the post-historical individual, shaped beyond the benjaminian and romantic tradition, or rather by himself absorbed. According to him, the era of electronic images added mutations and new problems to the translator. Nevertheless, Flusser himself noticed and absorbed these oscillations.

Keywords: Vilém Flusser. Translation. Benjaminiana.

No pequeno texto de 1990, "Pontificar", Vilém Flusser explora a ideia da tradução como construção de pontes. Aí ele afirma que os pontífices (construtores de pontes) seriam essenciais, hoje mais do que nunca. Eles deveriam permitir o trânsito não apenas entre as diversas línguas (trânsito impossível, mas necessário), como também entre o discurso verbal e o imagético, entre o conceito e o algoritmo, entre a música e as demais linguagens. Traduzir implicaria um "salto entre universos". Se traduzir equivale a "levar de um lado para o outro" esta atividade é metáfora (no sentido etimológico desta palavra). Mas se, por outro lado, Flusser precisa que "tradução e metáfora não são a mesma coisa", ele não deixa de enfatizar - ponto essencial para ele - que "pensar e traduzir são sinônimos, e não apenas para poliglotas" (FLUSSER, 1998, p. 199). Ser "judeu" para ele significava encarnar esta tarefa pontifical de oscilar e transitar entre universos. Sua Bodenlosigkeit (falta de chão, de terra e de fundamento) abria-lhe a perspectiva de ser um nômade entre as diversas línguas e linguagens. Ao mesmo tempo, de sua "ponte" ele via que as disciplinas, nações e linguagens específicas são nômades e vivem de uma constante crise e de um fluxo que põem em questão as suas identidades, como o próprio indivíduo deve ser visto como um tal fluir. Ele tinha como projeto que toda a humanidade pudesse se tornar Bodenlos e praticar o pontificado. 
A sua situação de exilado e esta reflexão sobre o dispositivo de identidade como um dispositivo xenófobo e "outricida" lançam também luz sobre a sua potente teoria da Heimatlosigkeit (apatricidade), tal como lemos no ensaio "Wohnung Beziehen in der Heimatlosigkeit (Heimat und Geheimnis - Wohnung und Gewohnheit)". (FLUSSER, 1992, 2007) Aqui trata-se também de modo explícito de uma reflexão retirada da sua própria experiência de vida. Daí esse trabalho ter sido acolhido no volume autobiográfico Bodenlos. Esse texto é um fruto da reflexão do seu autor sobre a sua origem judaica em Praga e sobre seu exílio de mais de trinta anos (entre 1940 e 1972) em São Paulo. Ele se inicia com uma descrição do autor que conclui com estas palavras: "Em suma, sou heimatlos, porque muitíssimas pátrias [Heimaten] se armazenam em mim. Isto se manifesta diariamente no meu trabalho. Eu sou apatrizado [beheimatet] em pelo menos quatro línguas e me vejo exortado e obrigado a traduzir e retrotraduzir tudo a-escrever [ $\mathrm{Zu}$ -Schreibend]" (FLUSSER, 1992, p. 247). Deste fato ele também deduz seu interesse pela comunicação, pelos buracos entre os lugares e "pelas pontes que cobrem estes buracos" (FLUSSER, 1992, p. 247). "Talvez este interesse pode ser deduzido do meu próprio pairar [Schweben] sobre estes lugares", ele arrematou. O seu texto de um modo geral se apresenta como uma reflexão teórica a partir deste "transcender das pátrias". Ele parte, nesta teoria, da diferença entre o gesto de habitar e o de ter uma pátria. O ser humano desde os tempos mais remotos sempre habitou algum lugar, mas apenas recentemente se tornou agregado a uma pátria, Heimat. Esta é a protoverdade que o exilado Flusser descobre a partir da sua "ponte". "Nós, os incontáveis milhões de migrantes (sejamos trabalhadores estrangeiros, exilados, fugitivos ou intelectuais andando de seminário em seminário), nos reconhecemos não como excluídos [Aussenseiters], mas antes como vanguardas [Vorposten] do futuro" (FLUSSER, 1992, p. 249). Ao invés de pessoas dignas de pena, estes deslocados seriam "modelos", pois a migração, além de ser um sofrimento, é uma ação criadora. 


\section{O mundo são as imagens que criamos}

E o conceito de criação é justamente fundamental no pensamento de Flusser, esse filósofo que pensava por imagens e construindo ficções filosóficas na tradição de pensadores como um Platão ou Rousseau. Sua teoria das imagens técnicas pode ser colocada ao lado da reflexão benjaminiana sobre a obra de arte na época da sua reprodução técnica. Ela desdobra também a crítica benjaminiana da escrita alfabética linear, que foi desenvolvida, sobretudo no livro sobre o Trauerspiel ${ }^{1}$. Esquematicamente podemos dizer que Flusser foi o primeiro a perceber a profundidade das ideias de Benjamin sobre a fotografia e a reprodução técnica. Ele expandiu e superou esta teoria no sentido de uma reflexão sobre as imagens técnicas. Benjamin ainda pensava com uma cabeça educada dentro da clausura da textolatria que alcançara, segundo Flusser, seu apogeu no século XIX. Benjamin foi o primeiro a descrever com clareza as consequências da fotografia, mas ele ainda não detectara seu potencial de transformar a sociedade com a mesma profundidade que ocorrera, como formulou Flusser, quando da introdução da agricultura e da pecuária no neolítico (FLUSSER, 1985, p. 70). Se Benjamin foi um dos grandes críticos do historicismo e percebeu que a era da reprodução técnica é uma era pós-tradição (para ele na era da fotografia não caberia mais se fazer uma diferença entre cópia e original nem se falar de autenticidade), Flusser vai notar, por sua vez, que o historicismo era o resultado de uma luta milenar entre a escrita e as imagens e que o homem pós-histórico é fruto do novo triunfo das imagens sobre a escritura. Na fotografia ele viu antes de mais nada um dispositivo, a saber, um aparelho que funciona como uma caixa preta. (Para uma filosofia da caixa preta, 1983 [1998]) O mais importante - e que Benjamin não notara - é que não precisamos saber como ela funciona para dominá-la. A fotografia abre a era pós-hermenêutica, pós-deciframento, em suma, com ela passamos a lidar com o mundo via uma "capacidade imaginativa de segunda ordem" (FLUSSER, 1998, p. 36). A fotografia também é comparada em importância à invenção da escrita 
(FLUSSER, 1998, p. 37) e com a passagem para a posição ereta e correspondente liberação das mãos (FLUSSER, 1985, p. 52). As imagens técnicas teriam para ele como tarefa reunificar o pensamento e libertá-lo do império do conceitual. Benjamin, que praticou e teorizou um modo de pensamento imagético, teria ficado no meio do caminho dessa revolução ao não perceber a gravidade desta tensão entre as imagens e o verbal. Mas o caminho que Flusser identifica na revolução aberta pelas imagens técnicas só poderá ser trilhado se praticarmos uma crítica radical destas mesmas imagens. Pois estas estão sob a égide de programadores que apenas querem impor suas mensagens. A imagem técnica nasce, por assim dizer, fascista e o fascismo histórico seria o auge deste culto das imagens. Na sua filosofia da caixa preta Flusser concluía que caberia a nós criticar uma sociedade dominada por aparelhos, já que estes nos dominam como uma espécie de Golem (FLUSSER, 1998, p. 89). A crítica da fotografia coincide para ele com uma crítica do funcionalismo - que permanece urgente e na ordem do dia.

Já em seu livro Ins Universum der technischen Bilder (No Universo das Imagens Técnicas), de 1985, ele aprofunda esta teoria das imagens técnicas e a fotografia assume um papel menos importante como sendo uma espécie de pioneira das imagens técnicas, mas ainda anterior às imagens eletrônicas que agora assumem o primeiro plano de suas reflexões. Nessa obra, Flusser aprofunda sua crítica da sociedade moderna com Bildfuncionären (funcionários das imagens) ao mesmo tempo em que apresenta uma nova sociedade dialógica e telemática composta por Bilderzeugern (criadores de imagens) e Bildersammlern (colecionadores de imagens). Essa sociedade puramente informacional seria composta por pessoas livres, criadoras e colecionadoras de imagens - uma utopia, portanto, com tons baudelairianos e benjaminianos. Com efeito, o modelo crítico de Flusser que no ensaio Filosofia da caixa preta tendia mais para uma distopia, assume agora um caráter mais próximo de uma utopia. Como em Benjamin, vemos nessa filosofia da tecnologia e da mídia um entrecruzamento com a filosofia da história, da linguagem e da tradução. Flusser continua atrás de seu projeto- 
-pontificado, pensando aqui na circulação entre línguas, linguagens e entre o passado, o presente e o futuro. Sua visão de um tempo fora do tempo, de uma não história absoluta capitaneada pela era das imagens técnicas, é tão vertiginosa quanto à de Benjamin que apontava também para uma sociedade na qual passado, presente e futuro se encontrariam sob a égide de uma sociedade sem exploração e sem violência. Em Flusser - como em Benjamin - essa utopia nasce da sensação de Bodenlosigkeit. Se Benjamin diferenciava entre imagens auráticas e pós-auráticas, distinguindo desse modo a pertença ou não à tradição, Flusser distingue imagens tradicionais das técnicas. Estas últimas são feitas por pontos, são pós-históricas e correspondem ao computar e calcular. As imagens tradicionais para Flusser seriam "intuições de objetos" e, portanto, englobam as duas categorias de imagem benjaminianas. Na era das imagens técnicas os criadores de imagem podem se libertar do pensamento linear conceitual que até agora reprimia o universo das imagens. Mas não se trata da volta das imagens tradicionais, ligadas ao mundo da magia e do eterno retorno, mas sim do mundo onde impera a Einbildungskraft (imaginação criativa), onde o Zufall (acaso) não é mais visto como Unfall (acidente), mas sim como Einfall, descoberta, insight (FLUSSER, 1985, p. 18). Se podemos reconhecer aqui uma analogia com a admiração romântica e benjaminiana pelo (witzger) Einfall (achado chistoso), essa aproximação vai, na verdade, mais longe, já que reencontramos em Flusser, como vimos, a valorização de um conceito de identidade como fluxo, suspensão (Schweben), como também Schlegel e Novalis - e Benjamin na linha deles - haviam formulado. Mas em Flusser essa noção de fluxo ganha o peso de uma imaterial descarga elétrica e o mundo explode conectando o Tzimtzum (a "contração" originaria de onde surgiu o mundo, na tradição cabalística judaica) ao Tikkum (a restauração do paraíso), explosão originária e recriação. O mundo é desvelado como uma chuva de pontos de realidade e trata-se, via Einbildungskraft, de sabermos acelerar estes pontos. Se em Benjamin já víamos um elogio da superfície, de sua observação e leitura, Flusser descreve uma nova era na qual não nos contentamos mais em 
ler a superfície do mundo, mas sim aprendemos a produzi-la com imagens. Via Einbildungskraft podemos concretizar com imagens, pois não se trata mais de explicar, narrar e de todas as modalidades do pensar linear. Não se trata tampouco de reprodução quando falamos de imagens técnicas, mas sim de sintetizar, de produzir. Como McLuhan, também para Flusser os meios são as mensagens (Cf. FLUSSER, 1985, p. 55). Já conceitos benjaminianos ganham novos significados quando ele escreve: "As pessoas querem ser distraídas/espalhadas [zerstreut] para não precisarem, como ocorre no diálogo de fato, se reunir [versammeln] e se recolher [sammeln]." (FLUSSER, 1985, p. 72) Esta utopia imagética telemática e computacional pode parecer muito distante do universo de ideias de Benjamin, mas não se trata aqui de repetição, de imitação ou de continuidade, mas antes de ruptura. Flusser, como Benjamin, teve a ousadia de tentar inventar novas imagens para pensarmos nossos limites e fronteiras.

\section{Tópicos para uma leitura da "tradução" como dispositivo na teoria flusseriana das imagens técnicas}

Se o físico tradicional ainda acreditava na diferença entre imagens verdadeiras e falsas, Flusser fala da nova superficialidade na qual não existe mais o "problema do verdadeiro e do falso" (FLUSSER, 2008, p. 42). Ele vislumbra uma "maré de imagens técnicas vitoriosas" (FLUSSER, 2008, p. 85). Fala do fim da política, da história e do trabalho. Finalmente estamos "livres para conferir significado ao mundo, sintetizando as informações recebidas sob forma de imagens". Ou seja: a história da cultura se torna, como em Benjamin, citation a l'ordre du jour; lembremos-nos de sua ideia de coleção, na qual tudo é ressignificado, numa nova síntese que implica um metabolismo do passado. Mas em Flusser, de modo muito mais enfático que em Benjamin, trata-se de uma tradução intersemiótica, no sentido das imagens, de ideias antes pensadas no registro do logos verbal. As imagens sintéticas são definidas como superfícies sobre as 
quais aparecem os resultados do diálogo entre memórias artificiais e humanas. Nesse diálogo ocorre uma tradução "de código de zero-dimensionalidade para código de bidimensionalidade". Imagens traduzem conceitos claros e distintos (FLUSSER, 2008, p. 111). E ainda: "As imagens sintéticas tornam imagináveis as teorias as mais abstratas" (FLUSSER, 2008, p. 112).

Flusser fala também da sociedade utópica na qual o homo faber passa a ser homo ludens (FLUSSER, 2008, p. 96). Essa sociedade telemática: é composta por "gente livre que produz informações imagísticas e imaginárias em diálogo cósmico", trata-se da "superfície imaginária que fluirá sobre o abismo" (FLUSSER, 2008, p. 97). Nessa sociedade utópica a "vertigem da queda se transforma em vertigem da aventura" (FLUSSER, 2008, p. 97-8).

Já em "Planung des Planlosen", de 1970, ou seja, poucos anos antes da segunda grande emigração de Flusser, ele defendera a figura do viajante e de seu gesto, nascido de repente, de abandonar o seu local: "A partida é libertação do hábito, e a decisão de se partir é o tomar uma liberdade fundamental: a do movimento. Sem ele não valeria mais a pena viver." (FLUSSER, 1994, p. 40). O errante Flusser defende suas rupturas com argumentos que empenham a dignidade de toda a humanidade. Ele vê no viajante um Homo ludens, alguém que aposta no acaso, arrisca-se, mas ao mesmo tempo vive de modo integral a sua liberdade. Talvez ele não estivesse equivocado aqui. Afinal a teoria é, como ele também afirma pensando na sua etimologia grega, "sight seeing" (FLUSSER, 1994, p. 39), e de fato Flusser viu muita coisa e pôde decantar dessa leitura do mundo palavras que guardam uma sabedoria. Como o Benjamin dos anos 1930, Flusser aproxima constantemente em seus textos sobre a viagem e sobre o nomadismo Fahren (viajar) e Erfahren (fazer experiência), que encontra a sua correspondência na relação de experiência com o latim ex-periri. "É correto que aquele que se senta [der Sitzende] possui [be-sitzt] e o que viaja [der Fahrende] experiencia [erfährt], ou o que se senta habita o hábito e o que viaja corre perigo [Gefahr]" (FLUSSER, 1994, p. 59). Na viagem coexistem tanto a experimentação, como 
a ousadia, a prova e o perigo. Daí Flusser criar também uma falsa etimologia entre Wagen (carro) e Wagnis (ousadia) (FLUSSER, 1994, p. 45). Esse ser humano móvel, ele escreveu em um texto cheio de humor sobre o Wohnwagen (Trailer), de início dos anos 1970, seria a resposta à consciência triste que Hegel já detectara no homem moderno, dividido de modo dialético e sem saída, entre a sua esfera privada e a pública. O homem pós-histórico seria, para Flusser, aquele capaz de abandonar esta tristeza e transformá-la em alegria via engajamento com o mundo. Ele mantém a revolta e se apega à emigração, este ser que está livre de uma moradia fixa, engaja-se na mudança e no seu risco implícito.

Flusser descreve a história da sociedade como a história de programas que já contém em si a sua superação. As rupturas são momentos de superação e criação de novos programas. As imagens sintéticas e a telemática permitem uma tal ruptura (FLUSSER, 2008, p. 115). Se estamos na era da síntese, podemos entender que também estamos em uma era pós-reprodução, e também, numa cultura pós-tradução. O saltar, über-springen, e o traduzir, über-setzen, ainda supunham uma cultura histórica e um indivíduo descolado de sua esfera pública. O indivíduo póshistórico não é mais aquele que vimos acima, que Flusser formulou dentro da tradição romântica e benjaminiana, ou seja, o ser do fluxo diferencial; constante superação de si. Na era das imagens eletrônicas sintéticas novas imagens são confeccionadas e a elas correspondem tanto uma nova autoimagem do ser humano como a superação não só do ponto de vista histórico, mas de tudo o que estava conectado a ele, como, por exemplo, a própria noção moderna de tradução. Dai esse gesto de traduzir ter se tornado cada vez mais, ao longo do século $\mathrm{XX}$, um gênero literário e desponta hoje como uma das principais atividades de muitos poetas.

O teórico das informações Flusser recorda que as informações tendem a se recombinarem ao sabor do acaso e a empobrecer. Apenas no momento criativo se evita este processo (FLUSSER, 2008, p. 117). “As imagens sintetizadas são, desde já, os primeiros fenômenos da criatividade disciplinada e apoiada sobre determinada 
teoria” (FLUSSER, 2008, p. 118). Poderíamos pensar a tradução como momento de energização e de injeção de criatividade em um universo de textos que, no geral, tendem à redundância. A criatividade é a decisão a favor do pouco provável em meio ao muito provável. Traduzir seguindo este ideal significa sintetizar, pós-traduzir: ser criativo. E para Flusser a humanidade torna-se conjunto de críticos criativos: "o 'pintor' futuro pode dedicar-se integralmente ao momento crítico, ao momento verdadeiramente criativo" (FLUSSER, 2008, p. 120). Se nos tornamos todos críticos e criativos, o tradutor como criador-crítico vai ressintetizar textos. Contra a entropia da repetição, da re-presentação, ele adere à criatividade sem limites.

Mas levemos mais adiante este exercício de pensar a tradução a partir da teoria das imagens eletrônicas de Flusser. Ele afirma: “As imagens técnicas, por sua multiplicidade automática, tornam supérfluo todo tipo de autoridade, seja ela 'maior' (fidelidade à fonte) seja ela 'menor' (administração da propagação da mensagem)" (FLUSSER, 2008, p. 125). Da mesma maneira podemos pensar a tradução na era pós-representação como se dando definitivamente para além de todo compromisso com a autoridade e a fidelidade: é pós-tradução. Flusser desenha sua utopia dizendo que nossos netos serão "artistas puros e criativos" (FLUSSER, 2008, p. 128). Uma nova espécie de homens surgirá, descarnada, pós-ética, política e ontologia. As imagens técnicas excluem perguntas como: "são elas verdadeiras ou falsas?', 'são elas autênticas ou artificiais?', e, sobretudo, 'o que significam?'." Essas imagens “são sonhos que excluem toda interpretação de sonhos". (FLUSSER, 2008, p. 128) Nem crítica, nem interpretação, nessa era pós-hermenêutica também não haveria mais espaço para se pensar a tradução em uma chave romântica/moderna. $\mathrm{O}$ mundo pré-cibernético ainda distingue o ativo do passivo. Isso não ocorre nas imagens técnicas, como se vê na fotografia. Homem e máquina são ativos e passivos (FLUSSER, 2008, p. 130).

Não surpreende que Flusser, em meio a essa visão profética (ou não) do mundo cibernético pós-histórico, em seu quase delírio 
que descreve o triunfo de um homo ludens cibernético, aproxime as imagens técnicas de uma arte pura como a música (FLUSSER, 2008 , p. 146). Essa arte foi tratada ao menos desde o romantismo como a arte mais capaz de se despir do caráter de mimese do mundo que marca as artes. Essa arte, que pode ser pura síntese, torna-se o modelo da criação das imagens eletrônicas. Se agora busca-se a "musicalização das imagens e a imaginação da música" (FLUSSER, 2008, p. 147), então a utopia da Bodenlosigkeit se concretiza sem que haja mais espaço para o jogo de diferenças. Polifonia pura, música das imagens, o mundo não é mais terra do tradutor, mas do artista cósmico. Cada um, conforme seu gosto e juízo, pode ler nisso uma utopia ou uma distopia.

\section{Nota}

1. Com relação à crítica benjaminiana da escritura alfabética linear e, de modo mais geral, sobre a teoria benjaminiana da escritura cf. meu artigo, SELIGMANN-SILVA, 2005. 


\section{Referências}

FLUSSER, Vilém. Von der Freiheit des Migranten: Einsprüche gegen den Nationalismus. Bensheim/Düsseldorf: Bollmann, 1994.

. Bodenlos: Uma autobiografia filosófica. São Paulo: AnnaBlume, 2007.

. Bodenlos: Eine philosophische Autobiographie. Bensheim/Düsseldorf: Bollmann, 1992.

. Kommunikologie. Frankfurt am Main: Fischer, 1998.

. Ins Universum der technischen Bilder. Göttingen: European Photography, 1985.

. O universo das imagens técnicas: Elogio da superficialidade. São Paulo: Anna Blume, 2008.

SELIGMANN-SILVA, Márcio. Walter Benjamin e os sistemas de escritura. In: . O local da diferença: Ensaios sobre memória, arte, literatura e tradução. São Paulo: Editora 34, 2005. p. 123-140.

Recebido em: 12/02/2014 Aceito em: 23/05/2014 